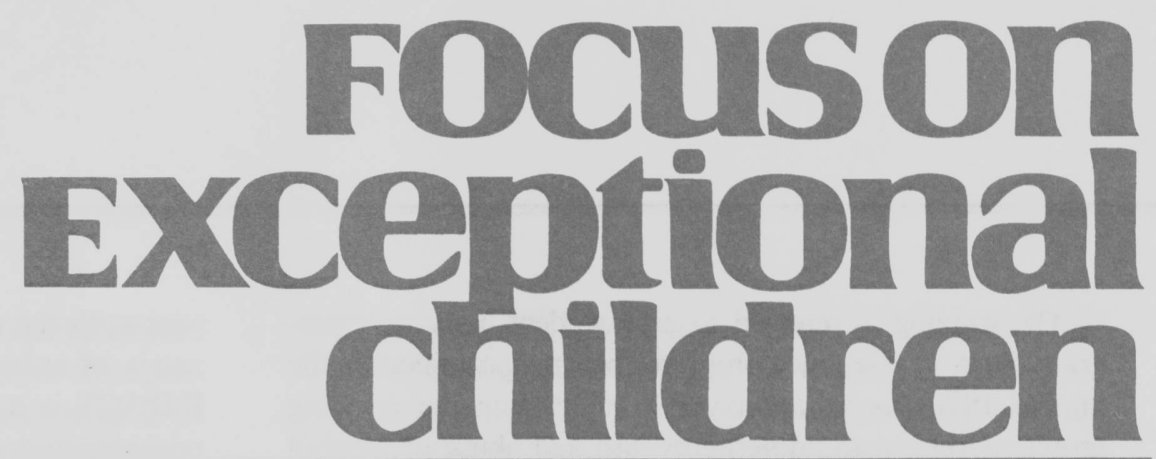

\title{
Promoting A Safe School Environment Through A Schoolwide Wellness Program
}

\author{
Patricia A. Gallagher and Linda S. Satter
}

When school officials have metal detectors at school entrances for weapon checks, conduct random drug testing of athletes, use breathalyzers to detect alcohol, inspect lockers, forbid pagers and cell telephones, and install video cameras in buses, they are doing so to protect youth from injury and tragedy. "Although some safety measures may need to be in place, this approach cannot be at the forefront of safe school plans (Lantieri, 1997, p. 157).

A balance can be created between promoting safe school environments through inspection practices and surveillance equipment and presenting a comprehensive wellness program that promotes a positive and supportive environment. School curricula should be taught by competent and caring teachers who provide students with experiences in problem solving and decision making strategies and opportunities to practice responsibility and respect. Teachers need to involve students as active participants and collaborators in program activities and extracurricular experiences to help them undertake commitments that encourage and reinforce kinder and gentler relationships.

IMPACT is such a program. It is a comprehensive high school program that promotes a positive and supportive environment by involving students, faculty, and the community in a variety of prevention, collaboration, and intervention activities in response to students' needs. The long-range goal of the program is to equip students with essential skills to be healthy adults.

\section{ORIGIN OF THE TOTAL WELLNESS PROGRAM}

The program at North Kansas City High School (NKCHS), a small community adjacent to Kansas City, Missouri, grew out of an incentive grant written by the building principal to secure funding for safe-school training. The grant enabled eight of her teachers and some from area high schools to complete 36 hours of professional training through the Baptist Medical Center in Kansas City, Missouri.

Patricia Gallagher is a Professor in the Special Education Department, University of Kansas, Medical Center. Linda Satter is IMPACT Coordinator, North Kansas City High School, North Kansas City, Missouri. 
The training is referred to as a student assistance program. Student assistance programs became prominent in the middle 1970s as an approach to addressing the growing problems related to adolescents' use and abuse of alcohol and other drugs. Over the years, advocates of student assistance programs realized that substance abuse is the result of, and is accompanied by, many problems. These include parental drinking or substance abuse, family frustrations with rearing children in today's culture, teenage depression and suicide, teen pregnancy, sexually transmitted diseases, divorce, and nicotine addictions.

As a result, the original training expanded to address the many and varied issues affecting adolescents today. It taught the adult learners the roles they can play to improve the school climate, promote students' self-image, and provide a home base where students can go to get help. As such, the program emphasized a comprehensive program designed to meet adolescents' needs. It also encouraged participants to find and network with human and community resources to assist the youth and their families. Essentially, the program teaches the value of enabling.

From its "humble" beginning, which focused on keeping kids in and drugs out of school. IMPACT expanded each

\section{FOCuson
Exceptional children}

ISSN 0015-511X FOCUS ON EXCEPTIONAL CHILDREN (USPS 203-360) is published monthly except June, July, and August as a service to teachers, special educators, curriculum specialists, administrators, and those concerned with the special education of exceptional children. This publication is annotated and indexed by the ERIC Clearinghouse on Handicapped and Gifted children for publication in the monthly Current Index to Journals in Education (CIJE) and the quarterly index, Exceptional Children Education Resources (ECER). The full text of Focus on Exceptional Children is also available in the electronic versions of the Education Index. It is also available in microfilm from Xerox University Microfilms, Ann Arbor, MI. Subscription rates: Individual, \$30 per year; institutions, \$40 per year. Copyright (C) 1998, Love Publishing Company. All rights reserved. Reproduction in whole or part without written permission is prohibited. Printed in the United States of America. Periodicals postage is paid at Denver, Colorado. POSTMASTER: Send address changes to:

\section{Love Publishing Company \\ Executive and Editorial Office \\ P.O. Box 22353 \\ Denver, Colorado 80222 \\ Telephone (303) 221-7333}

Edward L. Meyen

University of Kansas
Glenn A. Vergason

Georgia State University

Richard J. Whelan

University of Kansas Medical Center year with the addition of innovative programs to meet the needs of safety in the school and community. Currently, IMPACT is a total wellness and awareness program that provides students with a support network of peers, teachers, parents, and school and community programs. It is designed to recognize troubling trends and respond to societal changes that can consume the lives of youth and drive some from the education system. The ultimate outcome is to provide students with the necessary skills to be healthy adults.

When the initial group of North Kansas City High School teachers returned from their student assistance training, they reported their experiences at a faculty meeting. Their enthusiasm for what could be done at the school was contagious and encouraged other colleagues to become part of this new wellness program. Now when new faculty members arrive at the school, they are encouraged to take the training offered at Baptist Medical Center.

Students learn about the program's activities during registration and the freshmen orientation session. Throughout the school year posters and announcements are made inviting students to join.

Block-scheduling arrangements give students and staff members interested in the IMPACT program opportunities for participation. This scheduling allows students to meet their seven classes on Monday and four 85-minute classes from Tuesday through Friday. Two of these classes are designated as seminar times encompassing a variety of activities. For example, students can use seminar time to plan skits, organize events, and present lessons to children in nearby elementary and middle schools. Teachers are assigned to five classes, two planning periods, and three extra-duty assignments. Teachers can fulfill their extra-duty requirements by acting as sponsors for an IMPACT program.

\section{THE CURRENT WELLNESS PROGRAM}

IMPACT consists of two major components: a "participation" and a "helping" component. The participation component is composed of a variety of student activities that include SAVE, peer mediation, Impact Improv, SADD, Hi-Step, PAL, high school heroes, and TRY. The helping component includes PATHS, a student's resource officer services, individual counseling, community counseling services, conflictresolution meetings, support groups, ethical decision-making and problem-solving workshops, teen institute, and referral services to outside agencies. The following descriptions will reveal an interconnection between these two major components of the wellness program.

In addition, there is a complementary relationship between IMPACT and the school discipline policies and procedures. For example, peer mediation may be an alternative to suspension or arrest. If word reaches IMPACT that a 
potential fight may erupt, the likely violators can be offered a mediation session that potentially can prevent a suspension or arrest. Peer mediation also has been used after an incident that resulted in disciplinary action. In this case, mediation assists the violators to think ahead to acceptable responses if a similar incident, temptation, or problem should arise.

\section{Participation Component}

\section{SAVE}

Students Against Violence Everywhere is a group of concerned students who work closely with local police departments and community agencies to find ways to decrease violence in the schools and communities. The program was designed to address violence in the high schools and to carry the message that school is a safe environment. At first it was concerned with six topics: gangs, cliques, weapons, students feeling like outcasts, racial problems, and drugs.

SAVE began in 1991 when the Kansas City, Missouri, Police Department decided that a comprehensive program was needed to make the school environment safer. Faculty members at the four high schools within two school districts in the North Patrol Division of Kansas City, Missouri, were asked to provide a group of students that the police could talk to about violence in their schools. The students gave their perceptions of violence in the schools, and recommendations on how to combat it.

Students from each grade level in each high school were brought together to discuss the problem of violence in the area's high schools and to design a program that would address the problem. They suggested that the following three committees be formed to help carry out a series of activities as outlined below:

- a Student Steering Committee, composed of three students from each of the four high schools;

- an Administration Committee made up of representatives from law enforcement, the school administration, social service agencies; IMPACT coordinators from the four high schools who represented the teachers, and juvenile justice officers

- an Advisory Committee composed of community leaders.

Once the committees had been established, the following 10 activities were recommended as a means to address violence in the schools.

1. Mediation. Students were to be trained to serve as mediators to handle disputes between fellow students.

2. Police. Uniformed police were to be present in the school to interact with the students and to enforce the laws. The officer would instruct, counsel, and arrest.
3. Disciplinary procedures. The police would be called and appropriate action taken when students commit acts of violence in schools. Students would be disciplined by assigning them jobs at the school, such as assisting the custodians in cleaning the school or in the community, such as working at the city's recycling center. Suspension from school was not seen as punitive. Therefore, detention periods were recommended during the offender's free time, such as Friday nights and Saturday mornings.

4. Family counseling. Services were to be made available to families needing counseling assistance. This would include problem counseling for the students and assistance for parents who were having difficulty with parenting skills.

5. Awareness. As an initial effort to change some destructive attitudes of students and adults, it was recommended that publicity be generated about SAVE and the causes of violence in the schools.

6. Teen hotline. A hotline was to be established. Through the hotline, individuals could notify school administrators and the police about illegal activity, such as students carrying weapons and engaging in gang activity.

7. Legislation. Legislation was recommended for holding parents accountable for the weapons they have in their homes.

8. Student body. A cross-section of the student body was to give suggestions to students with disciplinary problems.

9. Activity night. Occasional nights were to be designated for dances at a neutral place for all high school students.

10. Questionnaire. A questionnaire was to be developed and distributed to all students to secure their perceptions of violence in their school and to solicit suggestions on how to combat violence. This was to be the basis for further program development.

As an initial step, the Student Steering Committee developed a questionnaire and gave it to each student in the four high schools. More than 4,000 students responded. The questionnaire and responses are shown in Figure 1.

After the responses to the questionnaire were analyzed, the Student Steering Committee, faculty, school administrators, IMPACT coordinators, law enforcement personnel, and social service agencies proceeded to implement their safe school programs. North Kansas City High School implemented the following.

- A faculty member teaches students to mediate disputes between peers. This peer mediation enables students to negotiate differences before they escalate. 


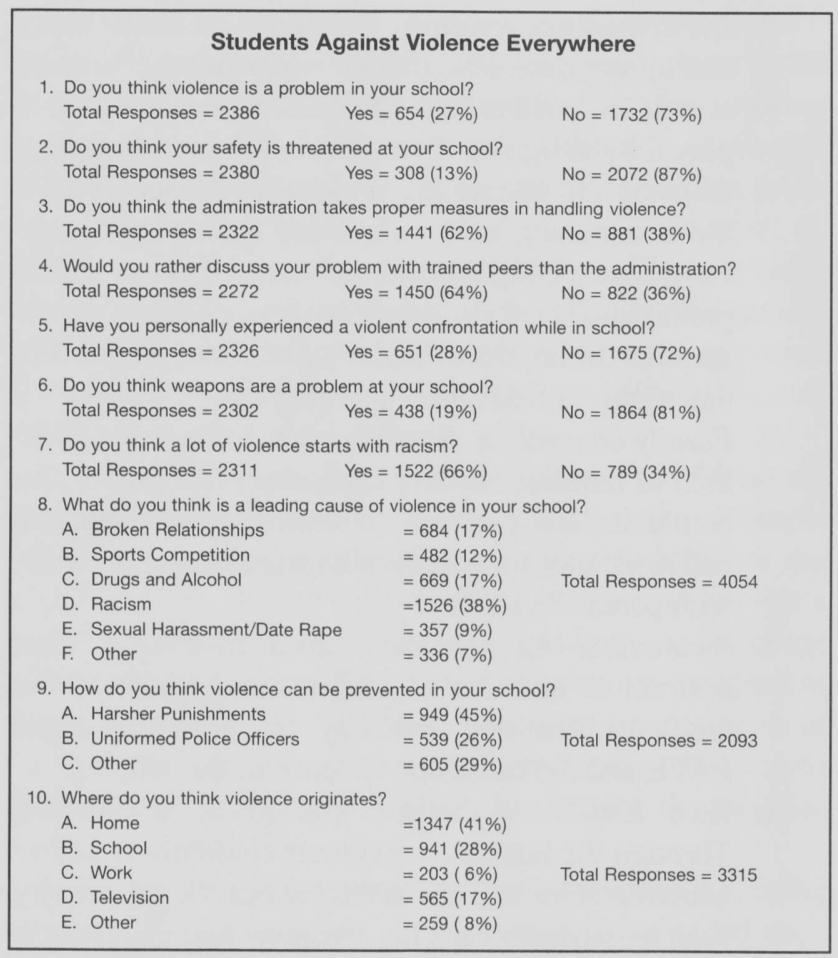

\section{FIGURE 1 Results of Questionnaire}

The training also covers information on racial and cultural differences.

- A uniformed police officer is present. The officer is available to teach in the classrooms; assists in counseling sessions with students, and serves as a liaison between the school and outside agencies, such as the county juvenile justice personnel. In addition, the officer takes reports and makes necessary arrests.

- A disciplinary procedure requires parent involvement and alternative solutions to after-school detention periods. Detentions are on Friday from 2:40 p.m. to 5:00 p.m. Parents or guardians are asked to check their child into the detention period.

- A process enables students to work out personal problems and directs students and their parents to family counseling. A youth and family service agency provides services including counseling, a place for runaways, and a girl's home. The program offers a 24hour hotline for personal problems. The telephone number is displayed on a SAVE poster.

- Displays of SAVE posters and SAVE certificates for participating classrooms endorse the SAVE concept. The poster, designed by a student, contains two telephone numbers: one number for personal problem counseling and the other for reporting illegal activity.
- A method has been established to report illegal activity. Students call to report illegal activity anonymously. The Kansas City Crime Commission, staffs the telephone number, and contacts the appropriate school administrator to report the information. When necessary, the school administrator works with the police to address the activity.

- Mandatory reporting of violent activities is required. Missouri Code, Chapter 12.3, requires that certain crimes be reported to the police; therefore, every school has to report violent crimes to the police who would handle each case on its merit. During a meeting, representatives from the juvenile justice system informed the students, police, IMPACT coordinators, and administrators about prosecution for juvenile crimes.

- A curriculum that addresses violence is in place. The material promotes a decrease of dating/domestic violence and abuse of children and their families. In addition, it advocates prevention in educational videos and during lectures and discussions. The program is designed to promote (a) effective interpersonal communication skills, (b) conflict resolution in a peaceful manner, (c) self-awareness and appropriate identification and expression of feelings, and (d) awareness and understanding of the dynamics of abusive relationships. The program is taught by classroom teachers who have been trained at a facility for abused children and adults.

The SAVE program is reviewed annually. When the first year ended, new Steering Committee members were selected to replace graduated seniors. In addition, a brochure was designed to describe the SAVE programs. Funding was secured from an advertising agency and a printing company to have a brochure printed for every student in the four high schools.

Among the comments of SAVE students is the following from a junior who plays varsity football and plays golf. $\mathrm{He}$ said the program had a direct effect upon him by helping curb his tendency to get involved in fights.

I had a short quick temper. I've learned to control it and realize there is no point giving into violent behavior. I have other solutions and ways out. I will back off.

Another student shared his experiences:

SAVE has given me the opportunity to voice my opinion of how we should deal with the growing amount of violence. Not only have I told my ideas, but I see them going into effect.

\section{Peer Mediation}

Peer mediators are students who, with adult supervision, help resolve disputes between students. Issues that create 
disputes include rumors, threats, name-calling, fighting, and loss of property. Peer mediators are selected for their abilities of fairness, reliability, and good communication. In addition to training in effective communication techniques, problem solving, and critical thinking skills, they are taught a conflict resolution approach wherein disputants have the chance to sit face-to-face and talk uninterrupted so each side of the dispute is heard.

As the outside persons who lead the discussion, peer mediators do not take sides, and they keep all information confidential. After the disputants relate their versions of the incident the mediators define the problem. Then the mediators and disputants brainstorm options to resolve the conflicts and write them on the Brainstorming Worksheet form (Figure 2). They discuss what could have been done differently, what they can do to solve the immediate dispute, and what options they could choose if a similar problem should arise again in the future. When a solution is reached and agreed upon, it is written on the Peer Mediation Agreement Form (Figure 3), which the disputants and the mediators sign.

After the conflict resolution session, the peer mediators are responsible for completing a self-evaluation form designed to encourage the student's mastery of the mediation skills (Figure 4). Mediators receive feedback and support throughout their work with peers.

Brainstorming Worksheet

List all the possible options.
W What could be done to resolve this dispute?
- In the future, what could you do differently?

1.

2.

3.

4.

5.

6.

7.

8.

9.

10.

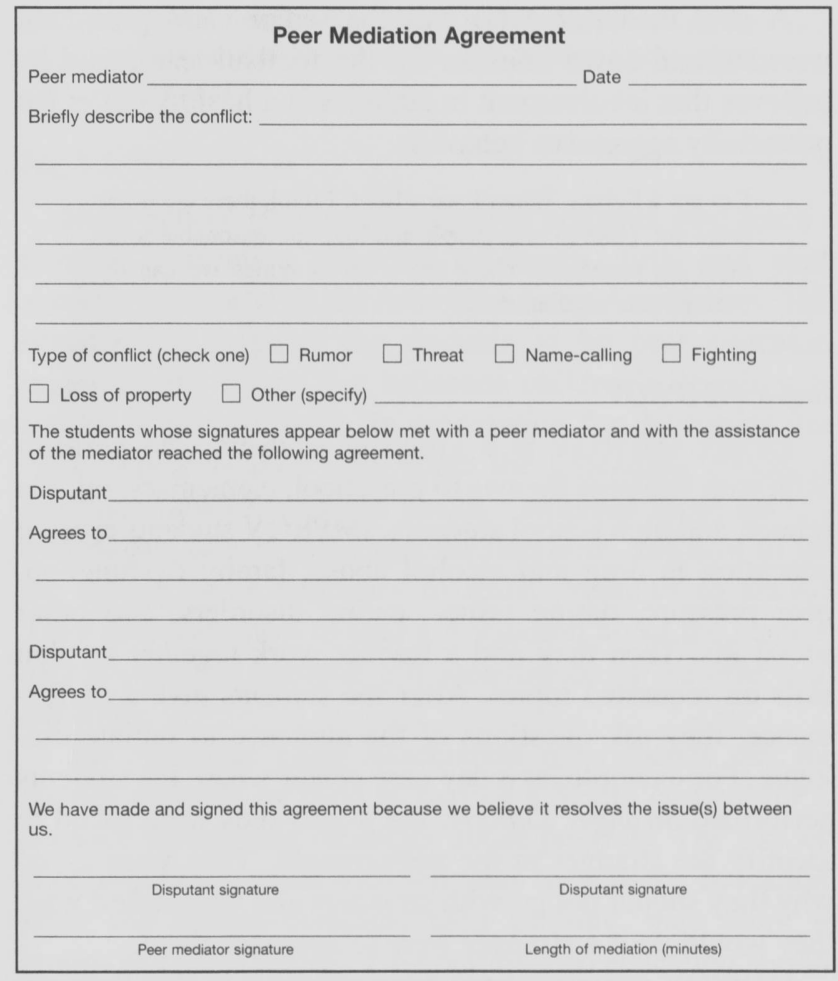

FIGURE 3

Peer Mediation Form

Peer mediator Peer Mediator Self-Evaluation
Directions: Place a checkmark $(\mathcal{V})$ by each step where you did quality work. Place an asterisk (")
by each step where you think the quality could improve.
$\square$ Step 1: Open the session
$\square$ Step 2: Gather information
$\square$ Step 3: Focus on common interests
$\square$ Step 5: Evaluate options and choose a solution
$\square$ Step 6: Write the agreement and close
1. What did you do well?
2. If you could do this mediation again, what might you do differently?
3. Were certain steps more difficult for you than others? If so, what could you do to strengthen
these steps?

FIGURE 4 Peer Mediation Self-Evaluation 
A peer mediator, who was the senior class president, wrestler, and down lineman for the football team, said he believes that involvement in athletics is a healthy outlet for potentially aggressive behavior:

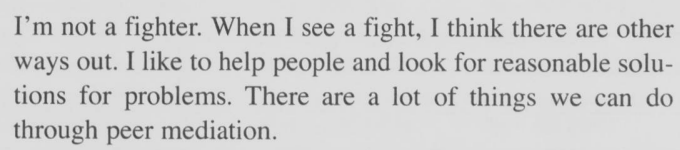

\section{Impact IMPROV}

Impact IMPROV is a group of students who perform skits with wellness themes to preschool, elementary, middle school, and high school students. IMPROV students receive education in drug and alcohol abuse, family dysfunction, peer pressure, dating issues, eating disorders, and other social ills. Then they and a teacher work together to plan skits on requested topics. After the students give a performance, they ask questions of the audience to initiate dialogue. For example, at a day care center where the students performed Stranger Danger, the 4-year-olds were asked to identify the stranger in the performance. They were asked why they should not go with strangers and were asked what they would do if a stranger were to approach them.

IMPROV activities have been effective in that they not only keep everyone's attention but also elicit great conversations. One of the actresses said,

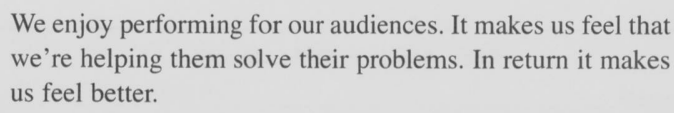

We enjoy performing for our audiences. It makes us feel that we're helping them solve their problems. In return it makes us feel better.

IMPROV activities are described in a brochure circulated to the elementary schools and in verbal communications with civic groups. Requests for performances come from elementary counselors, teachers, day care centers, civic groups such as the Rotary, church groups, and PTAs. During the past year, IMPROV performed at four elementary schools during each of five lunchtimes. In addition, the group does after-school, breakfast, evening, and weekend performances. Requests are now coming in from other cities and school districts.

Thank-you notes have come from preschool children, parents, teachers and community members. The group has become very popular. Demands for after-school performance have become so extensive that IMPROV has been included in the school's Drama II class.

\section{$S A D D$}

Students Against Destructive Decisions (formerly known as students against drunk drivers) is a program designed to raise students' awareness of the dangers of drinking and driving. To reinforce its message, the group engages in a number of activities throughout the academic year. For example, in May SADD presents a skit to demonstrate the risks of drinking and driving. During a mock scene, SADDs members wear "fatal vision" goggles that simulate the effects of alcohol by impairing their ability to walk a straight line.

In a docudrama held outdoors, police, medical technicians, squad cars, and ambulances join the SADD group for a DWI mock car accident. The emergency personnel attend to the accident victims, and the police question the witnesses to highlight the consequences of drinking. After the audience has watched the scene, they wear "fatal vision" goggles to learn firsthand how vision, coordination, driving skills, and mental judgment become impaired after drinking. Thus, the potential for fatal consequences becomes very real. The goggles give students the opportunity to understand the dangers of alcohol and drug ingestion without actually experimenting with them.

SADDs also send birthday cards, with a quarter enclosed, to sophomores when they turn 16. Students are encouraged to use the money to call home for a ride if they have been drinking. A week in the fall is designated Red Ribbon Week. This is a time when students are asked to wear red ribbons to remind everybody of the dangers of drinking and driving. During this week SADD also places small white crosses on the school grounds to demonstrate how many teenagers die daily in alcohol-related deaths. During Christmas week the student body is encouraged to stay safe over the holidays.

\section{Hi-Step}

High School-Taught Elementary Program is a cross-age teaching program in which high school students teach fourth graders about peer pressure, conflict mediation, drug and alcohol abuse, and relationships. Two faculty members sponsor the program.

Because Hi-Steppers are viewed as role models for the younger students candidates are carefully screened. They are chosen for good academic records and having an interest in helping fourth grade students grow emotionally and socially.

Hi-Step students receive their training during late winter and early spring. They attend an 8-hour training session to become familiar with the characteristics of fourth graders, learn to investigate topics, plan activities, and learn to write lesson plans. After their training, Hi-Step participants develop six lessons. Students meet with one of the sponsors weekly during seminar time to review their lessons, receive feedback, and practice with the other students in their group.

After the six lessons are ready, the group is assigned to an elementary school. Hi-Steppers are responsible for meeting with the fourth grade teachers and setting up times to meet with their classes. For this purpose, the Hi-Steppers have permission to leave high school during the seminar times. They have time to arrive at their assigned elementary school 
and teach the hour-long lessons with their accompanying activities, and returning before their own academic periods begin.

Although publicity for the program is done in the classrooms through the school's television channel and posted flyers, the most compelling publicity comes from the enthusiastic Hi-Steppers. Telephone calls start coming in October of the year preceding the performance.

Hi-Step experiences are great for the high school students who have a career interest in teaching or social services and for the fourth graders who have met teenage models. Hi-Step students tell how important they feel when they meet the fourth graders at the mall and are introduced to the parents.

The president of the Hi-Steppers summarized the group's intentions:

\begin{abstract}
If we reach one child, giving them the courage to do what is right, then we've met our goal. We want kids to know that their high school years can be a great time in their lives if they make the right decisions, and we help them to realize what those good decisions are. Most of all, we want them to know that we care.
\end{abstract}

\section{PAL}

Peers Always Listen (PAL) provides a group of students to whom other students can talk. PALS make a commitment to do what they can to encourage a positive and supportive atmosphere at the school. PALS do not give advice but, instead, listen and try to help their peers sort out their feelings. Consequently, all PALs receive training in assertive listening skills. They learn that emotion can be "energy" in motion and that the best way to defuse an emotional moment is to give the excited student an opportunity to "let the air out." They accomplished this by listening attentively. A student who is "highly charged" may talk only in syllables or phrases. A PAL listens until the peer is able to express himself or herself coherently. PALs are committed to the positive action of listening with care.

PALs also take part in other IMPACT programs such as SADD and IMPROVS. They tutor, distribute, and hang red ribbons for Red Ribbon Week and participate in activities that have the potential to improve the school atmosphere. They welcome new students and help them adjust to school.

One of the latest activities to be included in PAL is to spend some seminar time in a special day school for students who have behavior disorders. PALs engage in nonacademic tasks such as playing board games, shooting baskets, and making crafts. They have been well received by the students and teachers alike.

A PALs participant stated,

The group teaches students how to be more aware of their peers' feelings and about themselves. It introduced me to many new students like myself who are interested in the well-being of their classmates. The training teaches great people skills.

\section{High School Heroes}

High School Heroes is a group of students who teach a tobacco prevention program to fourth, fifth and sixth graders, sponsored by the American Lung Association. This organization prepares the students to be peer educators regarding the forces that influence children's decisions to smoke or not to smoke. In preparation for their roles, the High School Heroes learn about the immediate effects of smoking, how to reinforce positive attitudes about being a nonsmoker, how to make specific decisions, and how to use the refusal skills necessary to resist pressures to smoke. They also learn how to lead a discussion about the respiratory system that includes a demonstration of the effects of smoking.

The American Lung Association recommends that the Heroes program be used as part of a health curriculum to enhance the existing substance abuse program. The Association provides a guide with activities for tobacco education. After the Heroes complete their training, they work in groups of five to prepare a 1-hour tobacco education lesson. After completing their lesson work, they contact fourth-, fifth-, and sixth-grade teachers to set up times for delivering their lesson.

The Lung Association suggests that peer education can have a significant influence on students' knowledge and attitudes about smoking. They believe their training can have an impact on high school students' leadership skills and can reinforce positive attitudes about being a nonsmoker.

\section{TRY}

Teaching and Reaching Youth (TRY) is composed of parents and community members from business, police, the service agencies, and education. Its main purpose is to engage the community in focusing on developing knowledge, attitudes, and skills concerning tobacco, alcohol and other drug abuse, and related wellness issues. Specific efforts familiarize the community with state laws, school district policy, and local ordinances relating to these topics. The group's mission is to promote physical and mental wellness in young people through community involvement.

TRY recognizes that youth can be at risk when drugs and alcohol are present during social events. It knows that some students will be pressured by peers to participate. Therefore, one of its programs is Safe Homes for Teens, in which information is sent to parents to secure their support in providing safe homes for student parties. Safe Homes provides homes free of drugs and alcohol. Safe Home parents have access to other committed parents who have pledged to support this 
cause. TRY has also met with hotel and motel managers requesting that they deny room reservations to prom students who seek accommodations for their parties.

TRY has provided some of the financial support for a popular annual youth activity, school lock-in, in which the SAVE group is also involved. A lock-in provides a safe environment, such as a community center, for a night of social activities that include music, dancing, basketball, swimming, gameroom fun, food, and nonalcoholic beverages.

Some of TRY's other activities include sponsorship of Red Ribbon Week with a community kick-off rally. The group purchases ribbons to tie on utility poles and trees, and yard signs caring the message Drug Free and Proud throughout the city. TRY also sponsors community PIE (Parent Informational Evenings) nights. Here, speakers from the community share information about current topics-for example, the issue of methadone laboratories and what to do about their accessibility to the youth. Methadone labs, for some reason, are prevalent in the surrounding area; hence the need to address the situation.

\section{Helping Component PATHS}

Practical and Academic Transitions to High School (PATHS) is a 3-week summer course designed to prepare eighth graders for a smooth transition to high school. During this course incoming students receive an orientation to the school and community and participate in a special curriculum that promotes student bonding and thematic learning.

For the development phase of PATHS, the building principal recruited a group of teachers interested in the PATHS concept. They developed the summer program, an environment in which students making the transition from middle school to high school could feel more secure and successful. The principal presented the idea to the central office and received funding for the 3 -week program.

Two faculty members became co-directors of PATHS. They were joined by four teachers, an instructional assistant, and an attendance secretary to develop the summer program's activities. Peer helpers representing a diverse student population were also selected to give special presentations to middle school students, the potential participants for the summer program.

Peer helpers serve as tutors, conflict mediators, teacher assistants, and hall monitors. They operate the school store during the breaks, are group leaders in the homerooms, and run errands.

In the first PATHS program in 1994 four middle schools enrolled 91 students. They received one-half elective credit for attending all the sessions and completing assignments. The five peer helpers received credit also. The 3-week program began with student bonding activities that continued into week two and week three, which focused on thematic learning.

Week 1. The main objective of the first week was to encourage the students to bond as a team and to become oriented to the school and community. The activities were as follows:

- The Challenge consisted of high and low rope courses designed to teach cooperation, communication, peer support, team building, and self-confidence through a series of well supervised physical challenges. Students spent a full day off campus at an adventure site in the woods.

- Being Successful focused on characteristics that successful people have in common. These include being responsible, hard-working, and team players, as well as going the extra mile. Students became acquainted with successful peers and guest speakers who taught the school's expectations for its students. They were asked to reflect and write about someone whom they considered successful. In addition, they were instructed in the components of peer mediation leading to win/win situations.

- Community Orientation involved students in a picturetaking walking tour of North Kansas City. Students learned about aspects of the city including its history, architecture, and culture. The mayor welcomed the students and discussed city government. When the students returned from the day's adventures, they worked together to develop a travel brochure of the city.

- School Orientation familiarized the students with traditions of the high school. The students went on a walking tour of the campus and learned the buildings and locations of departments. Course offerings, transcripts, school rules, and expectations were discussed. Students became acquainted with the school planner, which they are responsible to keep during their freshmen year.

- Diversity Training was presented by Anytown USA, a program sponsored by the Council of Christians and Jews. It begins with participatory situations for students to experience being different, such as having the disability of blindness, deafness, or confinement in a wheelchair. These are followed by decision-making activities that promote an understanding of and appreciation for diversity of people in the community and school. The experiences encourage positive selfimage, communication skills, leadership ability, male/ female perceptions, police/youth relations, racial understanding, cultural awareness, and family and peer relationships. 
Week 2 and Week 3. A thematic learning experience focused on the music industry and provided continuity throughout the second and third weeks. A music theme was selected because of its appeal to the adolescents. Students attended three classes per day. At the end of each day, students assembled in the auditorium to participate in musical enrichment. A variety of musical groups performed, and students responded to and critiqued the performances. Three specific academic areas were imbedded in the learning: mathematics, communication, and study skills and are described as follows.

- The Mathematical Skill Program invited the students to use their skills to manage a band. They were responsible for scheduling performance events, figuring time cards, using charts and graphs to record number of performances and the time schedules, mapping travel routes, and writing paychecks. Students were scheduled individually to work in the Computer Curriculum Corporation, a programmed learning of computer use for the development of math skills.

- The Communication Skills Program prepared students to read, discuss, and analyze music reviews. Students wrote critiques of the musical performances they heard in the afternoon. They practiced proofreading skills and oral presentation of their work. They engaged in an art activity by making a collage around the theme of music.

- The Study Skills Program familiarized the students with teacher expectations. Students were taught techniques for previewing lessons and learning the value of understanding each section. Techniques for oral and written reviews also were taught and applied to the materials they were using in the thematic unit. Testtaking skills were presented. Instruction included the teaching of skills required to pass verbal, multiplechoice, and essay tests successfully. Students also were exposed to the assessment procedures the faculty used for grading assignments.

PATHS participants get together several times during the academic year. They have plays, speakers, and casual conversation periods to talk about how school life is going. The Peer Helpers have initiated many informal one-on-one meetings with the freshmen.

\section{School Resource Officer}

The School Resource Officer is available to assist students with various legal concerns. These concerns have been about abusive parents, abusive boyfriends, DUI arrests, traffic tickets, and probation contingencies.

The School Resource Officer program, begun in Phoenix, Arizona, in the mid-1980s, has been adopted by some police departments throughout the United States. The duties of the School Resource Officer in the IMPACT program are as follows:

1. To be a resource to instructional units to students on issues related to a basic understanding of the law and the role of law enforcement.

2. To be a resource for instruction to students on issues related to violence, prevention of violence, and personal safety.

3. To facilitate individual and small-group discussions based on material presented in class, or other topics such as date rape, driving while intoxicated, and automobile accidents relevant to student/officer interests. These groups take place during school time or outside of school time.

4. To hold conferences with students to assist them with problems regarding alcohol, other drugs, law enforcement, crime prevention, or personal safety.

5. To meet with students and make referrals to community agencies that offer assistance to youth and their families.

6. To provide informational services to the staff on issues related to alcohol and other drugs, the law, violence, gangs, safety and security.

7. To provide faculty training on skills related to violence prevention, violence diffusion, creation and maintenance of a safe environment.

8. To meet and interact with the Student Steering and Administrative Committees to assist them in any of the programs or legislative issues that SAVE is pursuing.

The SRO commented at the conclusion of his 4 years in the school.

\begin{abstract}
My job as an SRO has been a very rewarding period of my law enforcement career. I've been able to interact with, educate, and positively influence more kids over time than many officers do throughout a career. Since the inception of my role, the number of fights, gang activity, thefts, and drug-related cases has consistently declined. An SRO should be mandatory for every middle school and high school. The value of a safe school environment and the positive law enforcement presence cannot be overstated. SROs are a necessity in schools today. They not only assist in maintaining a safe school environment but also help in building responsible adults.
\end{abstract}

\section{Operation Drug Dog}

In 1997 the entire community took a proactive position on the drug issue by purchasing Twiko, a black Belgian Malinois dog, born and trained in the Netherlands for police work. His specialty is sniffing for drugs, especially marijuana, cocaine, heroin, and methamphetamines. Twiko became part of the community as a result of a campaign 
spearheaded by a trio of adults - the School Resource Officer, the IMPACT coordinator, and a mathematics teacher.

Although drug reduction efforts had been established in the school and community, not all drugs are found because they are concealed so easily. Teachers had been concerned about the prevalence of drugs in the community and how it was reflected in the school. Some students were returning "high" from open lunch and some were passing drugs on school grounds. At a faculty meeting the teachers said, "We're sick of losing students to drugs." The School Resource Officer, dedicated to the students' welfare, was adamant about finding ways, in addition to his work, to eliminate drugs from the school. The SRO, the IMPACT coordinator, and a mathematics teacher approached the school administration, police chief, community organizations, and city council regarding a plan, "Operation Drug Dog." They received approval, but not financial support, for the plan.

The School Resource Officer searched for other communities that had raised the $\$ 20,000$ required to cover the cost of the dog, his training, travel, kennel and cage, the travel lodging and training of the officer (who is not the SRO) assigned to Twiko. After finding a community that issued stock to raise funds, the trio decided to use that approach for fundraising. Stock was sold to individuals, including students and senior citizens, civic organizations, and corporations, for $\$ 10, \$ 25$, and $\$ 100$, respectively. Within 4 months the funds had been raised. The dog was purchased and trained with the officer. Then Twiko arrived to live in the community that owns him.

After his arrival each contributor was presented with a stock certificate and a photograph of Twiko with his officer. Their duties include night patrols, searching for drugs at sporting events, and random visits to the high school. There Twiko is treated to plenty of petting and attention. He is successful in sniffing out drugs, even minute amounts.

\section{Counseling Services}

Counseling services are available for individuals and groups during school hours and with a variety of community agencies. Students are referred by parents, teachers, friends, and self-referrals to the IMPACT coordinator, who devotes all her time to the role. Reasons for referrals include suspected drug and alcohol abuse, poor or failing grades, eating disorders, pregnancy, abuse, depression, and suicidal tendencies. When a student discusses a problem with the IMPACT coordinator, it is followed by an appraisal relevant to the type of support that will be needed. This may include school support, a community referral, a support group, or professional counseling.

The IMPACT coordinator contacts others, such as the parents, teachers, or community personnel, to gather pertinent information that will be useful in an intervention and treatment plan. If a student receives services outside the school, the coordinator is in contact with the agency to facilitate communications and coordinate everyone's efforts. In addition, if the student spends time in a treatment facility, the coordinator notifies the student's teacher, collects homework, and maintains communication between the agencies.

One student commented,

Being sent for treatment saved my life because it helped me realize that I did have things to live for and look forward to when I'm older.

A parent noted,

I really appreciate your efforts, your compassion, and your understanding during all of this with my daughter. We have been down a long, rocky road, and without the support of others like you, I don't think the ending of this story would have turned out nearly so well.

The IMPACT coordinator has seen a change in students' attitudes about getting help with their problems.

\begin{abstract}
It's no longer "un-cool" to talk about having problems. In fact, I can see where students have become more comfortable about dealing with their issues. I can't think of anything more important than the emotional well-being of our youth. If students aren't ready emotionally, they are never going to get it together academically.
\end{abstract}

\section{Grief Counseling}

Grief counseling became prominent in 1995, when the staff at NKCHS and other high schools throughout the United States recognized changes in the emotional health of students after traumatic events. Fatal and near-fatal injuries from accidents and acts of violence, as well as serious illness, were touching students' lives. When adolescents suffer grief from the loss, injury, or illness of someone they love, the emotional experience affects their behavior and can affect academic performance. They are particularly vulnerable to loss. "Grief is a keen and complex emotional experience that includes fear, anger, relief, despair, peace, guilt, numbness agitation and sorrow" (Naierman, 1997, p 62). As students go through the stages of bereavement, they do not always know that others are having similar experiences. In an effort to reach out to the students, NKCHS established guidelines to help the students heal. A plan was written describing an organized way to respond to a crisis.

During the time when the committee was working on the plan, a tragedy occurred: Four students were killed in an automobile accident. The developing guidelines were immediately put into operation, subsequently reviewed, and changes made. The IMPACT coordinator contacts community agencies for their support and obtains trained teachers to lead support groups. The guidelines delineate duties between the administrative team and the counseling team, 
and the lines of communication to students, staff, parents, community agencies, and the media. The teams provide crisis counseling and crisis rooms as long as they are needed. All activities are documented on a checklist for the management of a traumatic event.

\section{DATA AND RESULTS OF IMPACT}

The success of IMPACT is revealed informally by the participants in their comments cited throughout this article. In addition to these statements, data records for the number of student fights and student conflicts reveal a decline in student to student confrontations. Data on peer mediation illustrate an increase in the number of sessions. Figures 5 and 6

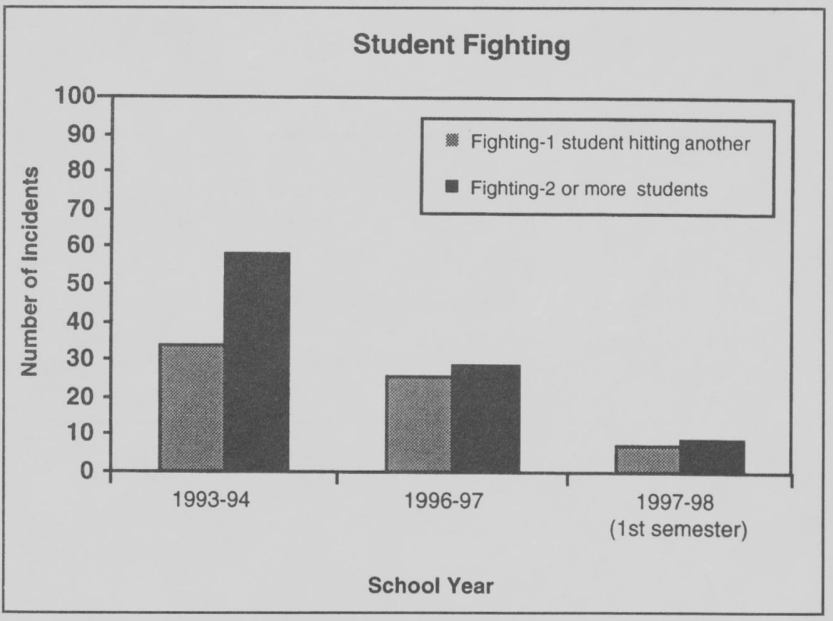

FIGURE 5

Number of Student Fights

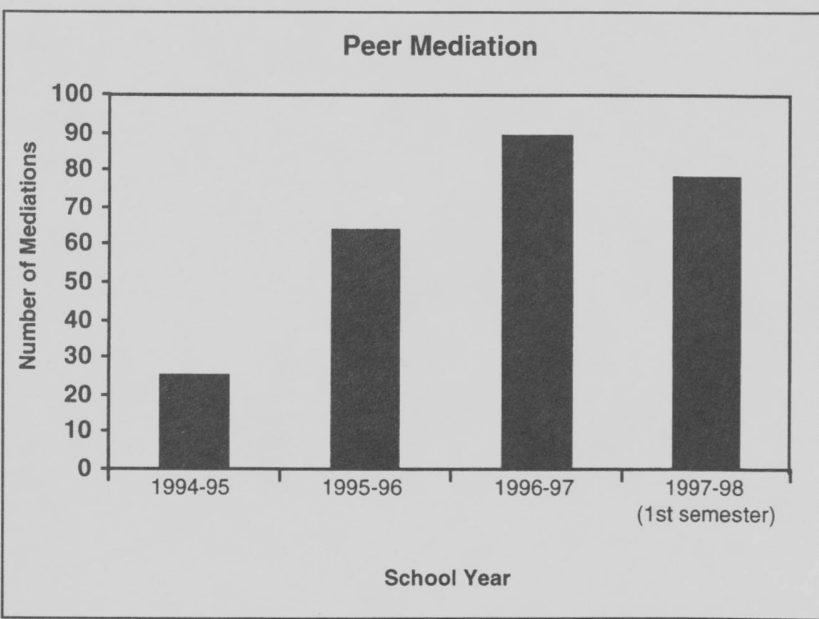

FIGURE 6 Number of Peer Mediation Sessions present these data. It is reasonable to assume that the following variables contributed to the decline of fighting: (a) The SAVE program had been initiated in the 1993-94 school year; (b) the peer mediation program was initiated in 199495; (c) a school resource officer was assigned to the school; and (d) a zero-tolerance policy relevant to fighting was implemented in the 1995-96 school year.

\section{SUMMARY}

One midwestern high school is taking proactive, constructive steps to protect students and strengthen their relationships with their peers, the faculty, and the community. The IMPACT program focuses on the importance of improving the entire school environment as a significant way to enhance students' wellness and safety. When students, faculty, and community members nourish inviting relationships, caring communities develop. Schools that implement only measures such as metal detectors, student identification badges, and locker inspections have confined themselves to solutions that are problematic. If, on the other hand, schools include practices that promote cooperation, teach conflict resolution, highlight the value of service to others, encourage empathy, and promote belonging and trust, they truly create safe schools.

\section{REFERENCES}

Lantieri, L. (1997). From punishment to prevention: Educating the heart. Reclaiming Children and Youth. 6:(3).

Naierman, N. (1997). Reaching out to grieving students. Educational Leadership. 55 (2).

We thank the many persons who have contributed to the success of IMPACT, the schoolwide wellness program, especially Evelyn Matthys, IMPACT coordinator for North Kansas City School District; Dr. Vicki Baker, Associate Superintendent of North Kansas City School District; Debbie Burns, Special Education Teacher; Rob Russell, School Resource Officer; IMPACT Care Team; IMPACT Student Participants; Bob Kelly and John Admire, Baptist Medical Center, Kansas City, Missouri.

\section{APPENDIX}

\section{Demographics of NKCHS}

North Kansas City High School (NKCHS) is one of three high schools serving the North Kansas City School District, which includes 20 elementary schools and four middle schools. The school is located in the small town of North Kansas City; therefore, most of the students are residents of the surrounding areas. The school district is north of the business and financial nucleus of metropolitan Kansas City, 
Missouri. It is a campus-style facility composed of five separate buildings, the oldest of which was constructed in 1925 .

The population represents nearly a complete cross-section of socioeconomic groups. Primary employers of the parents include the major airport, federal and state government agencies, automobile, electronic, paint, and agriculture industries.

The school has 1,400 students. The ethnic make-up of the school is $90 \%$ caucasian; the minority populations are represented equally by African American, Asian American, and Latin/Hispanic American cultures.
The school is a Missouri A+ school. A major benefit of this designation is that students who plan to attend a Missouri 2-year community college or vocational school after graduation may be eligible for State-reimbursed fees, books, and tuition. To be eligible, a student must complete the standards for graduation set by the school. In addition, the student must (a) have attended an A+ school for at least 3 years, (b) maintain $95 \%$ attendance, (c) have a 2.5 grade-point average on a 4.0 scale, (d) complete 50 hours of unpaid tutoring or mentoring, and (e) maintain good citizenship.

\section{PERMISSIONS AND COPYRIGHT}

All rights are reserved. No part of this publication may be reproduced, photocopied, faxed, stored in a retrieval system, or transmitted, in any form or by any means, electronic, mechanical, recording or otherwise, without the prior written permission of the publisher.
Back issues are available for sale. Reproduction requires permission and payment of fees. It is illegal and a violation of federal copyright law to reproduce this publication without permission. Direct all inquiries to the permissions editor. 